This PDF is a selection from a published volume from the National Bureau of Economic Research

Volume Title: The Inflation-Targeting Debate

Volume Author/Editor: Ben S. Bernanke and Michael Woodford, editors

Volume Publisher: University of Chicago Press

Volume ISBN: 0-226-04471-8

Volume URL: http://www.nber.org/books/bern04-1

Conference Date: January 23-26, 2003

Publication Date: December 2004

Title: Limits to Inflation Targeting

Author: Christopher A. Sims

URL: http://www.nber.org/chapters/c9562 


\title{
Limits to Inflation Targeting
}

\author{
Christopher A. Sims
}

\subsection{The Two Faces of Inflation Targeting}

Economists should recognize that they have a history of proposing simple "nominal anchor" prescriptions for monetary policy that have eventually proved not to be very useful. If economists satisfy a demand for spurious technocratic solutions to the political and institutional pathologies that generate destructive episodes of deflation or inflation, they can do harm by diverting attention from the sources of the problem. Such nostrums can also be harmful, usually with a delay, by failing to work and thereby undermining the credibility of monetary policy. A cynical view might be that inflation targeting has become attractive less because of advances in our discipline than because of the demand for a replacement for the gold standard, monetarism, and exchange rate anchors.

There is some reason to hope, though, that inflation targeting is a "better nostrum." This anchor is something that people do in fact care about, rather than an "intermediate target." It is therefore likely to remain credible that the central bank is committed to its inflation target even though periods when its policies are having difficulties. This anchor is widely recognized not to be directly and immediately under the central bank's control. Inflation targeting therefore requires that the central bank explain how its current actions relate to its view of the future course of the economy and that it be explicit about how precisely it can control inflation.

But there are in fact bounds, set by fiscal policy broadly conceived, on the central bank's control over inflation. It may lose control of a deflation. Benhabib, Schmitt-Grohé, and Uribe (2001; hereafter BSU) show that an

Christopher A. Sims is professor of economics at Princeton University, and a research associate of the National Bureau of Economic Research. 
interest rate rule that satisfies the "Taylor principle," because of the zero lower bound on nominal rates, can lead inevitably to a deflationary spiral. ${ }^{1}$ They did not emphasize that the result depends on a decidedly peculiarlooking fiscal policy. Peculiar though it is, we see historical examples of something close to such a policy. To understand how such a policy can arise, it may help to step outside the framework of models that treat the central bank and the treasury as a unified entity with a single budget constraint.

The central bank may be faced with a fiscal policy that fails to make primary surpluses respond to the level of debt and thereby undoes any effort by the bank to restrict the volume of outstanding nominal liabilities. Loyo (2000) shows how a failure of fiscal backing for monetary policy can leave interest rate increases powerless to restrain inflation, and he applies his model to interpreting Brazilian experience. Even when what are usually thought of as appropriate fiscal policies prevail, there are generally competitive equilibria in which spiraling inflation leads to the disappearance of real balances. Such equilibria can be suppressed by "backup" policies that put a floor on the value of money, via either taxation or reserve holdings. But it is not automatic that such backup policies are credible.

As a theoretical possibility, moreover, the lack of a credible fiscal policy may open the door to equilibria in which accelerating inflation leads to demonetization of the economy, even when policies are also consistent with stable equilibria. This theoretical possibility may influence central bank thinking, even though it has rarely if ever been observed.

\subsection{Deflationary Traps via "Ricardian" Fiscal Policy}

In this section and the next we consider two models, both highly simplified, that display in stark form the nature of fiscal bounds on the ability to control the price level. There is no claim here of originality. The basic idea of the deflationary model is in the work of BSU, and the interest rate rule model is a variant of one worked out in Sims (2000). And these models in turn draw on early work on the fiscal theory. The point of displaying these models here is to provide some reminders of the ways control over the price level can fail and of how the failures depend on fiscal policy.

The first model we consider is not an inflation-targeting model in any sense. The BSU models it parallels consider interest rate policy rules that have, in much of the literature, been taken to guarantee a determinate price level. The BSU models therefore can be interpreted as showing that making interest rates respond to inflation in a way that would widely be thought

1. "Inevitably" is arguably too strong a word here. They find indeterminacy. But in a stochastic world, indeterminacy reappears at every moment, and any random perturbation of a nicely behaved equilibrium is likely to lead to the deflationary trap. 
of as guaranteeing that inflation stays close to target can instead leave the economy open to a deflationary spiral. The model we present here strips away nonneutralities, and even bonds and interest rates, to show that the type of fiscal policy BSU consider will produce their sort of result even without an interest rate rule. The pathology they display is likely to be possible whenever policy in effect provides a tax backing for money, as if monetary liabilities were interest bearing.

The model has many identical agents, choosing time paths for their consumption $C$ and money holdings $M$. They receive an endowment income of $Y$ each period and pay lump sum taxes $\tau$. They have time-separable logarithmic utility functions in $C$. They value money because increased real balances reduce transactions costs.

Agents:

$$
\begin{gathered}
\max _{\left\{C_{t}, M_{t}\right\}} E\left[\int_{0}^{\infty} e^{\beta t} \log C_{t} d t\right] \text { s.t. } \\
C(1+\gamma V)+\frac{\dot{M}}{P}=Y-\tau \\
V=\frac{P C}{M} .
\end{gathered}
$$

Government:

$$
\begin{aligned}
& \text { policy: } \tau=-\phi_{0}+\phi_{1} \frac{M}{P} \\
& \text { government budget constraint: } \frac{\dot{M}}{P}=-\tau .
\end{aligned}
$$

The first-order conditions of the representative agent are

$$
\begin{array}{ll}
\partial C: & \frac{1}{C}=\lambda(1+2 \gamma V) \\
\partial M: & \frac{\lambda}{P}\left(-\frac{\dot{\lambda}}{\lambda}+\frac{\dot{P}}{P}+\beta\right)=\frac{\lambda}{P} \gamma V^{2} .
\end{array}
$$

In continuous-time rational-expectations models like this one it is particularly important to keep track of what the model defines as being able to "jump" and what it constrains not to jump. Often this is done by listing variables that can jump and that cannot, but not every model is properly characterized this way. It is quite possible for certain functions of variables in the model to be constrained not to jump, whereas all the arguments of the functions individually are not so constrained. In this paper we use the convention that all equations representing constraints hold not only for all $t \geq 0$ but also in a neighborhood of $t=0$. First-order conditions, on the other hand, apply only for $t \geq 0$. Thus if a constraint equation contains a 
single dotted variable (e.g., the $\dot{M}$ in equations [2] or [5]), the dotted variable, because its derivative must exist in a neighborhood of $t=0$, is implied to have time paths continuous at $t=0 . .^{2}$ An equation that is a constraint and contains multiple dotted variables does not constrain each individual dotted variable to have an absolutely continuous path. In a linear equation, it will be only the linear combination whose derivative appears in the constraint that is constrained to be absolutely continuous. On the other hand, a variable like $P$ in this model, which appears "dotted" only as the highestorder derivative in first-order conditions, is constrained only to have a right derivative, with a possible discontinuity in its level at $t=0$.

Some algebraic manipulation allows us to derive from the first-order conditions and the model constraints the following differential equation in $V$ :

$$
\frac{\dot{V}(1+4 \gamma V)}{V(1+2 \gamma V)}=\gamma V^{2}\left(1-\frac{\phi_{0}}{Y}\right)-\frac{\phi_{0} V}{Y}+\phi_{1}-\beta,
$$

which, because its derivation uses first-order conditions, holds only for positive $t$, so that $V$ is allowed to be discontinuous at $t=0$.

If we assume $Y$ to be constant and impose the fairly reasonable conditions that $\phi_{0}<Y$ and $\phi_{1}>\beta$, but $\phi_{1}-\beta$ small, then this equation in $V$ has two steady states, a smaller one that is approximately $\left(\phi_{1}-\beta\right) Y / \phi_{0}$ and a larger one. The smaller is stable and the larger is unstable.

In this model the definition of $V$ and the social resource constraint $C(1+2 \gamma V)=Y$ together imply a monotone increasing relation between $P Y / M$ and $V$ for positive $V$. Thus we can conclude that every initial value of $P$ below some critical value is consistent with equilibrium, each implying a different initial $V$, and all these possible initial $V$ s imply the same limiting behavior-convergence of $V$ to the lower steady-state value. At this lower steady state for $V$, if $\phi_{1}>\beta$ and $\phi_{1}-\beta$ is small, we have that

$$
\frac{\dot{M}}{M}=\frac{\dot{P}}{\mathrm{P}} \doteq-\beta
$$

to first-order accuracy in $\phi_{1}-\beta$. Thus we have the same kind of behavior found by BSU: indeterminacy of the price level and convergence, from a wide range of initial values, to the same equilibrium of steady deflation.

It is not difficult to understand why this policy results in indeterminacy - the policy authority has committed to back the real value of money balances with taxes regardless of how large this real value might be. The policy therefore implies no nominal "anchor." Prices can fall to arbitrarily low levels, boosting real balances to arbitrarily high levels, and even though no

2. The derivative itself does not have to be continuous at $t=0$. What is required is that $M$ be absolutely continuous with a derivative defined except on a set of measure zero and with the time path of $M$ the integral of its time derivative. 
one has a transactions use for the additional real balances, the tax backing and resulting deflation make holding the real balances attractive.

Above the upper steady state, the price level explodes rapidly upward and velocity also rises rapidly. In fact, velocity converges to infinity in finite time. There is no violation of transversality or of feasibility conditions in these explosive equilibria.

In this model, simple, apparently realistic policies will eliminate the indeterminacy. For example, if the government replaces its "tax-backed money" rule (4) with a commitment to hold $M$ constant, the differential equation in $V(8)$ is replaced by

$$
\dot{V}=\frac{\left(\gamma V^{2}-\beta\right) V(1+2 \gamma V)}{1+4 \gamma V} .
$$

This equation has a unique, unstable steady state. Initial conditions with $V$ $<\sqrt{\beta / \gamma}$ imply $V$ converging to zero, but this entails here that $M / P \rightarrow \infty$. Since agents in this equilibrium have bounded consumption paths, their accumulation of arbitrarily large real money balances violates transversality, so these deflationary paths are not equilibria.

With either constant- $M$ or Ricardian policy, the inflationary paths that start with $V$ above its steady-state value are equilibria. They can be eliminated by an apparently simple policy, a commitment to back a minimal value for money with taxation. It is well known, though, that there have in fact been historical episodes of hyperinflation in which, far from using taxes to put a floor on the value of money, fiscal authorities have persisted in running primary deficits as inflation has accelerated to extreme levels. Furthermore, as we will discuss at more length below, some institutional frameworks aimed at ensuring "independence" of the central bank undermine the credibility of any claim to provide a tax-backed floor to the value of money.

With the Ricardian policy, real money balances grow very large on the paths toward the lower steady state and, in the case where $\phi_{1}=\beta$, grow without bound in equilibrium. The growth does not violate individual optimizing behavior, however, because the foreseen steady rise in taxes makes individuals see themselves as dependent on the deflationary real return on their money balances to maintain intertemporal budget balance. The usual argument that arbitrarily high real wealth with bounded consumption violates transversality fails because the real-balance wealth is offset by the discounted present value of future taxes.

Since in this abstract model the consequences of backing money with a Ricardian fiscal rule are undesirable, and since better policies are easily available, one might ask why we need pay any attention to these results. The Ricardian policy looks crazy because the model assumes homogeneous, freely marketable, nominal government debt or money. This makes it easy 
for the government to dilute the claims of existing asset holders by new borrowing, without obviously targeting a narrow and organized constituency. It also makes it easy for asset holders, were the real current market value of their holdings of government liabilities to grow while their future tax liabilities apparently did not, to try to turn their increased wealth into current purchases.

In Japan today, and probably also the United States in the 1930s, deflation has its strongest effect in increasing nonmarketable, heterogeneous government liabilities. Tomita (2002) explains the variety of ways in which Japan's explicit debt is less easily marketed, more concentrated in the hands of banks and government agencies, and less homogeneous than government debt in the United States or Europe. And it is widely understood that both in the United States in the 1930s and in present-day Japan, the existence of large institutions with negative net worth that grows more negative with declining prices creates implicit, nonmarketable government liabilities, via potential claims to bailouts, as prices decline. When price declines create perceptions of claims on future tax revenues via bailouts as fast as or faster than they increase the value of marketable nominal securities in the hands of the public, they can fail to produce any strong positive wealth effects.

Another route by which deflationary equilibria might arise is via central bank balance sheet illusion. ${ }^{3}$ We have seen in the United States just a few years ago a discussion of the consequences for the Federal Reserve balance sheet of the vanishing of the U.S. public debt. In simple macroeconomic models, the balance sheets of the central bank and the treasury are consolidated, so that the public debt has vanished when only debt held by the central bank remains. But in the recent policy discussions it was assumed that the Fed might need to turn to holding private securities as backing for monetary reserves. That is, it was assumed that the treasury would continue to tax to run surpluses to retire the debt held by the Fed. This is exactly the assumption of BSU's Ricardian fiscal policy, although BSU require further that as deflation proceeds the treasury will continually replenish the central bank balance sheet by further purchases of private assets as the real value of high-powered money increases.

In the case of the U.S. Federal Reserve, it may seem unreasonable that the treasury should see debt held by the Federal Reserve as a liability requiring tax backing or that the Federal Reserve should ever perceive a need to ask for treasury replenishment of its balance sheet. The Federal Reserve has a nearly perfectly hedged balance sheet, with most of its assets nominal U.S. government bonds and its liabilities mostly high-powered money. Even if it did somehow develop substantial negative net worth, why would

3. The discussion of balance sheet illusion here and the model below of inflation stabilization with reserves draws on the discussion in Sims (2000). 
this be a problem? Its high-powered money liabilities carry no explicit promise that they are redeemable, so there are no creditors whose demands could make negative net worth a problem.

But there are other structures for central bank balance sheets. The most common direction of deviation is toward holding large amounts of reserves in the form of securities that are not denominated in domestic currency and hence leave the central bank less than perfectly hedged. A good example is the European System of Central Banks, which holds most of its assets in non-Euro securities. This clearly introduces balance sheet risk and the possibility of the bank's arriving at a situation of negative net worth. While it is true that there is no explicit promise to redeem high-powered money, we shall see that for a bank that must rely on reserves rather than fiscal resources, any attempt to commit to stabilizing the price level or inflation will make net worth a concern. This fact may both limit the bank's ability to dampen fluctuations in inflation and contribute to inappropriate Ricardian policy behavior in a deflationary environment.

\subsection{Stabilizing Inflation, with Reserves or Tax Backing}

Here we return to modeling both bonds and money, so that we can discuss policy in terms of an interest rate rule, as has recently been standard practice. We also introduce a foreign currency-denominated asset, so that we can consider a central bank with reserves only and no access to a backup taxing power.

In Sims (2000) I considered a model like this one, but with a central bank that tries to control the price level. That model made the point, which is perhaps nearly obvious, that when the central bank tries to enforce an upper bound on the price level, it must either limit its goals when its net worth is negative (or might become negative) or else have access to fiscal backing that would restore net worth whenever necessary. The outstanding highpowered money, while carrying no explicit promise of redemption, acquires an implicit redemption value when there is a commitment to a bound on the price level. A central bank that relies on the value of its reserves to back its money issue cannot guarantee a value for the currency stock outstanding that exceeds the value of its reserves. If it tries to do so, it is likely to face a run. A bank that uses an interest rate rule that aims at control of the price level does not avoid the problem. To implement its interest rate rule, the bank will have to stand ready to supply bonds for highpowered money. Disturbances to the economy - for example, to the real interest rate - can require time paths for reserves that are not feasible without replenishment of the balance sheet by fiscal actions. The likelihood of this happening is greater the more seriously underwater is the central bank balance sheet and the more tightly the bank attempts to control the price level. 
Here we consider a policy authority that uses interest rate rules. Because in this model there is no tax backing of non-interest-bearing money, the model does not have the indeterminacy and deflationary equilibria of the BSU model. Nonetheless it retains the "inflationary demonetization" equilibria, which can be avoided only with tax backing or reserves.

We suppose an economy with a representative agent maximizing

$$
\int_{0}^{\infty} e^{-\beta t} \log C_{t} d t
$$

with respect to the time paths of $C, F_{P}, B$, and $M$, subject to the constraint

$$
C[1+\psi(v)]+\dot{F}_{P}+\frac{\dot{M}+\dot{B}}{P}=Y+\rho F_{P}+\frac{r B}{P}+\tau .
$$

Here $C$ is consumption, $v=P C / M$ is velocity of money, $F_{P}$ is private holdings of the real asset, $B$ is nominal government debt, $M$ is money (noninterest-bearing currency), $Y$ is an exogenous endowment stream, and $\tau$ is transfer payments from the government. The real and nominal interest rates are, respectively, $\rho$ and $r$.

The first-order conditions for the private agent are

$$
\begin{array}{ll}
\partial B: & \frac{\lambda}{P}\left(-\frac{\dot{\lambda}}{\lambda}+\beta+\frac{\dot{P}}{P}\right)=\frac{r \lambda}{P} \\
\partial F: & -\dot{\lambda}+\beta \lambda=\rho \lambda \\
\partial M: & \frac{\lambda}{P}\left(-\frac{\dot{\lambda}}{\lambda}+\beta+\frac{\dot{P}}{P}\right)=\frac{\lambda}{P} \psi^{\prime} \nu^{2} \\
\partial C: & C^{-1}=\lambda\left(1+\psi+\psi^{\prime} \nu\right) .
\end{array}
$$

These equations can be reduced to

$$
\begin{gathered}
r=\rho+\frac{\dot{P}}{P} \\
r=\psi^{\prime} v^{2} \\
\rho-\beta=\frac{\dot{C}}{C}+\frac{\left(2 \psi^{\prime}+\psi^{\prime \prime} v\right) \dot{v}}{1+\psi+\psi^{\prime} \nu} .
\end{gathered}
$$

As usual, the equations derived from first-order conditions hold only for $t \geq 0$, while the constraint (12) holds continuously. The only variable forced to be continuous at $t=0$ by this single private constraint is the artificial construct "cumulative real asset purchases by the private sector, valued at acquisition cost" - that is,

$$
\int_{-T}^{t}\left(\dot{F}_{P}(t)+\frac{\dot{M}_{t}+\dot{B}_{t}}{P_{t}}\right) d t .
$$


So instantaneous, discontinuous portfolio adjustments, swapping among $M, B$, and $F_{P}$, are not ruled out. Instantaneous changes in wealth can occur, but only via jumps in $P$ that revalue bond and money holdings. Instantaneous jumps in wealth via purchases or sales of assets are not possible, because they would have to draw on savings or dissavings, and consumption and income flow at finite rates.

The consolidated government budget constraint is

$$
\dot{F}_{G}=\rho F_{G}-r \frac{B}{P}+\frac{\dot{M}+\dot{B}}{P}-\tau,
$$

where $F_{G}$ is government holdings of the reserve asset. Substituting equation (20) in the private budget constraint gives us the social resource constraint

$$
C \cdot(1+\psi)+\dot{F}=\rho F+Y,
$$

where $F=F_{P}+F_{G}$ is total holdings of the reserve asset, by both private individuals and the government.

Assuming the central bank is the only government holder of the reserve asset and that government bonds are not held by the central bank, we get as the central bank's budge constraint

$$
\dot{F}_{G}=\rho F_{G}+\frac{\dot{M}}{P}-\tau_{B} .
$$

It is natural to assume that in normal times, when seigniorage $\rho F_{B}+\dot{M} / P$ is positive, the bank will transfer sufficient revenues to the treasury or the public that its reserves remain aligned with outstanding money balances. When seigniorage revenue becomes negative, we assume that $\tau_{B}$ is set to zero. It may seem that it would be better policy to prevent net worth from deteriorating by allowing $\tau_{B}$ to go negative, but here we are trying to model a central bank whose "independence" entails not being dependent on the legislature for funding bailouts when net worth goes negative.

Now suppose that the monetary authority adopts an interest rate rule that reacts to inflation, setting

$$
\dot{r}=\theta_{0}+\theta_{1} \frac{\dot{P}}{P}-\theta_{2} r .
$$

Note that this policy rule makes $r$ react to inflation with a delay, although the delay will be small if $\theta_{2}$ is large. This equation does not imply that $r$ and $P$ must have continuous time paths. It allows discontinuous jumps $\Delta r$ in $r$ so long as they are matched by corresponding jumps $\Delta \log P / \theta_{1}$ in $\log P$.

Using equation (17) to eliminate $\dot{P} / P$ in equation (23), we arrive at

$$
\dot{r}=\theta_{0}+\left(\theta_{1}-\theta_{2}\right) r-\theta_{1} \rho .
$$

If $\theta_{1}>\theta_{2}$, the unique stable solution to this equation is 


$$
\begin{gathered}
r=\theta_{1} \int_{s=0}^{\infty} e^{-\left(\theta_{1}-\theta_{2}\right) s} \rho_{t+s} d s-\frac{\theta_{0}}{\theta_{1}-\theta_{2}} \\
\frac{\dot{P}}{P}=-\rho+\theta_{1} \int_{s=0}^{\infty} e^{-\left(\theta_{1}-\theta_{2}\right) s} \rho_{t+s} d s-\frac{\theta_{0}}{\theta_{2}-\theta_{1}} .
\end{gathered}
$$

Note that despite the interest rate smoothing policy, $r$ must move immediately in response to jumps in $\rho$ that are expected to have any persistence. This entails $v$ jumping in response to shifts in $\rho$. Here $P$ jumps up when $\rho$ does, but $d \log P / d \rho$ is less than $-d \log C / d \rho$. $M$ must therefore decrease to allow the equilibrium jump in velocity. The interest rate-setting bank must therefore be concerned with having reserves on hand to meet sudden shifts in real rates.

The differential equation (24) in $r$ has unstable solutions in addition to the stable ones. The solutions that explode downward are unsustainable. They force $r$, and hence $v$, to zero in finite time. But this can occur only via $M / P$ going to infinity, and in this setup, with tax backing only for bonds, the upward explosion in $M / P$ violates transversality: agents will try to spend the high real balances, cutting off the deflation.

The solutions that make $\dot{P} / P$ explode upward have no such internal cutoff mechanism, however. Although they imply that the economy converges to a barter equilibrium, no market mechanism along the path to this outcome provides incentives to stop the explosion. If such paths do not occur, it has to be because of a backstop commitment, based on taxation or reserves.

A bank backed by a fiscal authority that can credibly increase its primary surplus to provide resources to redeem money at some fixed-ceiling price level can cut off the explosive paths. Of course, as we have already pointed out, fiscal authorities have historically continued to run primary deficits during high inflations, so that no such backstop commitment was credible. (Where such a commitment were credible, the model implies that the inflation would never get underway.)

A bank relying on reserves can set a fixed ceiling to the price level at any point where its reserves are adequate to redeem the entire stock of money. But if it follows the policy rule in equation (23), there is no guarantee that it can always be in this positive net worth position. It earns a return $\rho$ on its reserves, while the value of its liabilities $M / P$ either remains constant or grows at the rate of deflation. As long as there are no surprise jumps in the price level (or, what is equivalent in this abstract model, the exchange rate between reserve assets and domestic currency), the return on non-interestbearing money will be less than that on nominal bonds, and the bonds earn the same real return as reserves. Therefore a bank that has reserves whose value matches its liabilities always earns positive expected seigniorage if it is undertaking no open-market operations. 
However, if rising inflation requires rapid shrinkage of nominal money balances in order to implement the policy rule, seigniorage can turn negative. Along an unstable path, in which inflation accelerates and interest rates rise, the bank will of course be undertaking contractionary openmarket operations. Whether these force it into negative seigniorage depends on the nature of the demand for money. If money is "essential," in the sense that as velocity increases the public is willing to pay everincreasing opportunity costs to avoid further small decreases in real balances, then large rises in the interest rate can be accomplished with small rates of contraction in money balances, and seigniorage may remain robustly positive. If instead demand for real balances falls rapidly when interest rates reach high levels, then increasingly high rates of contraction in $M$ may be required for given amounts of increase in $r$. This can result in large negative values of seigniorage and hence in disappearance of reserves while nonzero money balances remain outstanding.

To illustrate these points, we consider a version of the model in which the transactions technology has the specific form

$$
\psi(v)=\frac{\gamma v}{1+\phi v} .
$$

This gives equation (18) the specific form

$$
r=\frac{\gamma v^{2}}{(1+\phi v)^{2}} .
$$

This implies that if $\phi$ is positive, there is an upper bound on the nominal interest rate, beyond which demand for real balances is totally extinguished. Also, with $\phi>0$ there is an upper bound on the fraction of income that can be absorbed by transactions costs. With $\phi=0$ nominal interest rates are unbounded above and transactions costs can absorb a fraction of income arbitrarily close to 1 .

We consider a scenario in which the economy begins in a steady state with zero inflation, real and nominal interest rates both constant at 2 percent per year. The policy rule has $\theta_{0}=.02, \theta_{1}=1.2$, and $\theta_{2}=1$. We consider an unanticipated drop in the real interest rate $\rho$ to a new level, 1.8 percent per year. A new stable equilibrium requires that the nominal interest rate drop to 0.8 percent, with a corresponding drop of 1 percent in the price level. The result will be a new equilibrium that again has a constant interest rate but now has steady deflation at 1 percent per year, lower velocity, higher real balances, and slightly higher consumption.

Suppose that instead the price level does not drop far enough, so that the nominal interest rate falls only to 1 percent. Because the price level is above the level consistent with a stable solution of the system, it sets the economy on a path of rising nominal interest rates. Consider the case where $\gamma=.02$, $\phi=.3$. This implies that in noninflationary steady state transactions costs 
A

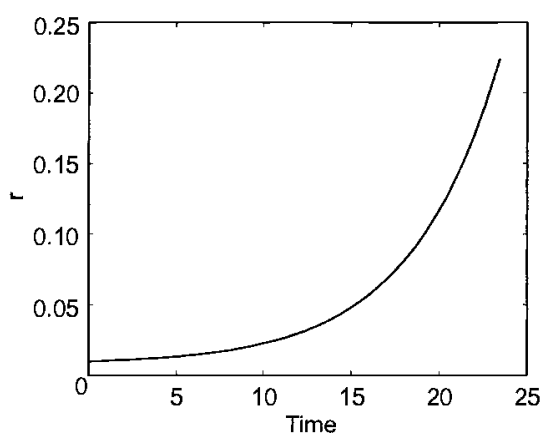

C

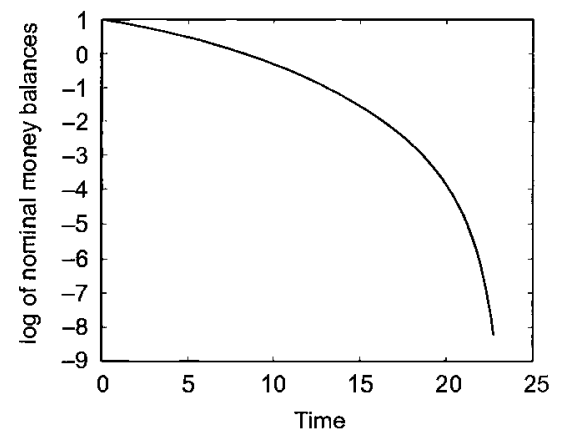

B

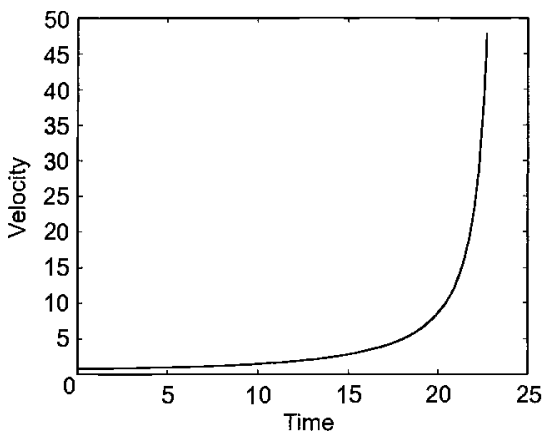

D

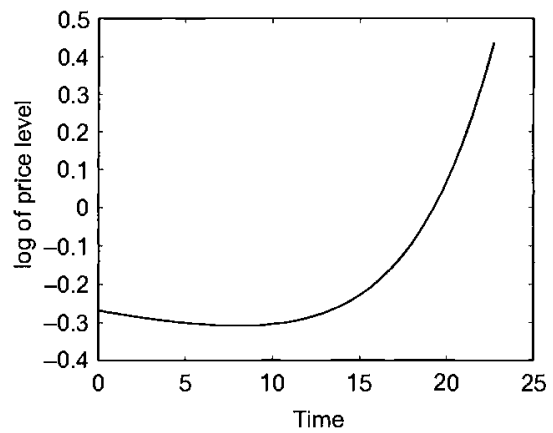

Fig. 7.1 Consequences of an insufficient response of $p$ to a $\rho$ drop

consume 2 percent of income and that there is an upper bound on the nominal interest rate, beyond which demand for money disappears, at 22 percent. The time paths for interest rates, velocity, the log of nominal money balances, and the log of the price level, are shown in panels A through D of figure 7.1 .

Whether or not a central bank reliant on reserves can extinguish this explosive path depends on its initial net worth position and its policy on distributing or accumulating seigniorage revenue. Assuming it accumulates all of its seigniorage revenue results in time paths for $F_{G} P / M$ as shown in figure 7.2. If its initial net worth is negative but it has assets worth 90 percent of its outstanding real balances at the initial date, then accumulating its seigniorage in the initial period allows it to achieve positive net worth, at which point it could cut off the inflation by announcing it will redeem money for the reserve asset at a fixed rate of exchange. But if its initial net worth is much below this, it never achieves positive net worth, and indeed its reserves hit zero before the date at which real balances disappear. Obviously this makes it impossible for the bank to continue implementing its interest rate policy rule with open-market operations. The likely outcome 


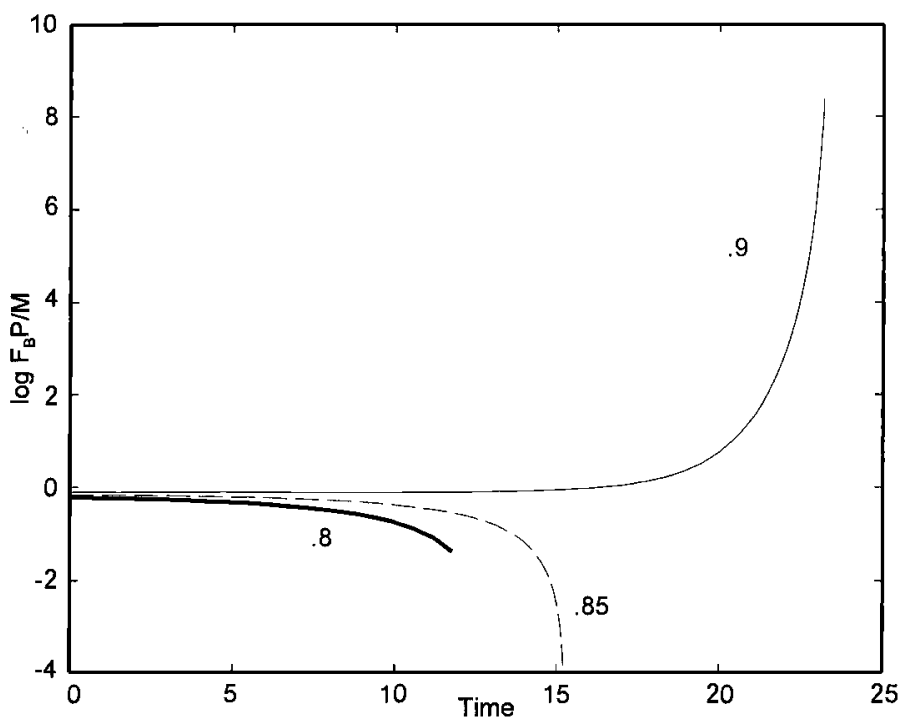

Fig. 7.2 Ratio of reserve to real balances outstanding under three assumptions about initial $F_{G} P I M$

would be an immediate jump to the barter equilibrium, and if this were foreseen, the jump would occur at the initial date.

That such scenarios are possible legitimizes attention to its balance sheet by a central bank that does not have reliable fiscal backing. The radical approach to central bank independence in the setup of the European Central Bank (ECB) — cutting all explicit connections with fiscal authorities and ruling out the holding of government debt as assets - has resulted in both an unhedged balance sheet and the absence of any explicit institutional structure for the ECB to use in case it were to need balance sheet replenishment. The Bank of Japan appears to be concerned that it would lose its recent gains in independence from the Ministry of Finance were it to arrive at a need for balance sheet replenishment. Records of monetary policy discussions in the United States in the 1930s show that there was concern about the "soundness" of assets being discounted by the Federal Reserve.

But in a deflationary environment, when the interest rate has hit its zero lower bound, the effective policy measures available to a central bank all carry balance sheet risk. This is obviously true of purchases of illiquid bank loans or of long-term government bonds whose current value will fall if deflation ends and interest rates rise. Even the "foolproof way" of Svensson (2001), which prescribes massive purchases of foreign currencydenominated bonds, because of the inherent volatility of exchange rates, creates substantial balance sheet risk for the central bank. 
Our conclusion is that a central bank can lose control of the price level during a liquidity trap episode because of timidity induced by balance sheet worries. These balance sheet worries are justified, if there truly is no fiscal backing for the bank, because of the opposite possibility, that a bank with negative net worth and no fiscal backing can lose control of the price level in an explosive inflation.

In our discussion of this model to this point, we have not paid any attention to fiscal policy. This can be justified only by assuming a passive fiscal policy that keeps real debt under control regardless of the path of inflation. Suppose instead, as in the scenario Loyo considers, the fiscal authority does not make the primary surplus respond to the level of the real debt. As an extreme case, suppose it sets the primary surplus to be constant. Then in this, as in many previous models of this type, going back at least to Sargent and Wallace (1981), there is no equilibrium with active monetary policy $\left(\phi_{1} / \phi_{2}>1\right)$.

Some economists believe that there is an asymmetry here, that when these incompatible monetary and fiscal policies are asserted, a firmly committed monetary authority can always prevail over any attempt by the fiscal authority to commit to an incompatible policy. But this is not true. It cannot even be discussed coherently in a conventional macro model with a unified budget constraint for the central bank and the treasury. If we introduce separate budget constraints for the central bank and the treasury, so that each can be imagined to possibly go bankrupt independently, we see that there is no formal asymmetry. If anything, the asymmetry is the other way. Central banks have died while the legislature that created them survived, but are there any examples of the reverse? And the lack of central, rational direction of the fiscal policy process in democratic countries probably makes it easier, not harder, for the fiscal authority to commit to a policy in the face of a threat (from the CB) that it could lead to disaster.

\subsection{Pros and Cons of Inflation Targeting}

It is plausible that the $\mathrm{CB}$ wants to bring inflation or deflation under control, even when it has recently been having trouble doing so. This may be less true of more artificial targets like $M$ growth or the exchange rate. The credibility of a commitment to inflation targeting may therefore be somewhat more stable. Because monetary policy can affect inflation only with a substantial delay, inflation-targeting central banks in practice produce explicit projections, generally quarterly, for a time horizon of about two years into the future. This entails their explaining, at least to some extent, how current policy actions are related to future objectives. This allows greater public understanding of policy, and thereby greater credibility. The delay means that there are generally many ways to get inflation into the target range over the policy horizon. This creates room for other objectives to 
affect policy choices, thereby further improving the alignment between the public rationale for policy choices and the actual interests of the polity.

Since there are conditions under which an inflation-targeting commitment, as a central bank policy, has a high probability of proving unsustainable, it should not be recommended in those conditions. It can easily lead to disaster, or to an apparent initial success that magnifies a later disaster, when the necessary fiscal backup to monetary policy is not available. It would not be a good idea in Argentina today, and it may yet prove to have been a mistake, or at least unsustainable, in Brazil. It can worsen the situation for a central bank that is at the zero bound on its policy rate and thus has no tools to influence inflation. A projection for a desirable path for inflation (or deflation) that cannot be backed up with an explanation of how current central bank actions are expected to lead to the desired path will undermine central bank credibility. Inflation targeting is therefore not in itself a policy prescription for the Bank of Japan.

\subsection{How to Improve It}

The main virtue of an influence-targeting regime is that it leads to increased transparency as to the objectives of the central bank and as to how the bank believes its current actions contribute to achieving those objectives. These aspects of the regime ought to be pursued even where (the United States?) the inflation target itself meets resistance. In fact, I would argue that if here, in contrast to other countries, the "inflation-targeting" label is a hindrance to getting the Federal Reserve Board to be more explicit about its projections of the path of the economy and about how its actions are expected to affect that path, it would be a good idea to abandon the campaign for inflation targeting.

We could extend the virtues of inflation targeting by accompanying inflation-report projections of inflation, output, and so on with projected time paths of the policy rate. We could improve central bank models so that they become capable of providing realistic probability bands on projections and can be invoked in explaining central bank policy choices to the public.

It would be a good idea to make explicit the conditional nature of the commitment to an inflation target. It is already well accepted that some kinds of "shocks" can push the economy away from the inflation target temporarily. When these occur, an inflation-targeting bank explains the source of the shock and explains its plans to bring inflation back into the target range over time. This enhances credibility, compared to taking drastic policy actions to get quickly back into the target range at the cost of a potential backlash from the political system.

Fiscal policy ought to be treated as a potential source of shocks. Ideally, where fiscal policy that undermines central bank control of inflation is a 
real possibility, this be should be accounted for, discussed in inflation reports, and reflected in central bank projections. Such proposals meet stiff resistance. They can be seen as threatening the current conventions of central bank "independence," which depend on keeping a firm distinction between fiscal policy, where political considerations are considered inevitable, and monetary policy, which is seen as a technical matter, ideally completely insulated from politics. (Recently Fed Staff, in conversation, cited the danger that Fed projections of fiscal variables would become public as a reason to maintain the five-year secrecy rule for Fed Green Book and model forecasts.)

Where there is little prospect of fiscal policy becoming a constraint on monetary policy, or of fiscal policy becoming the only instrument available for controlling the price level, detailed fiscal projections would not be important. But where there is such a prospect, the central bank is likely to be the leading candidate for an institution that can analyze the policy options for controlling inflation. As the designated steward of the inflation rate it could make a contribution by conducting and disseminating such analysis, even when it has reached the point where its own policy levers are not effective.

\subsection{Conclusion}

Inflation targeting is in most countries an improvement in the monetary policy regime. But the improvement comes from its being a step toward goal and model transparency. Inflation targeting is a dubious recommendation in precisely those economies where advice from economists about controlling inflation is most needed. If we separate the transparency aspects of inflation targeting from its nominal-anchor-nostrum aspect, we may come up with a more widely applicable policy recommendation. The central bank should probably everywhere be charged with making projections of inflation, laying out policy actions that could stabilize inflation, and either taking those actions or explaining why it cannot and who could.

\section{References}

Benhabib, Jess, Stephanie Schmitt-Grohé, and Martin Uribe. 2001. The perils of Taylor rules. Journal of Economic Theory 96:40-69.

Loyo, Eduardo. 2000. Tight money paradox on the loose: A fiscalist hyperinflation. Harvard University, John F. Kennedy School of Government. Technical report.

Sargent, Thomas J., and Neil Wallace. 1981. Some unpleasant monetarist arithmetic. Quarterly Review of the Minneapolis Federal Reserve Bank 5 (3): 1-17.

Sims, Christopher A. 2000. Fiscal aspects of central bank independence. Princeton 
University, Department of Economics. Technical report. Available at http:// www.Princeton.edu/ sims.

Svensson, Lars E. O. 2001. The zero bound in an open economy: A foolproof way of escaping from a liquidity trap. Monetary and Economic Studies 19 (S-1): 277312.

Tomita, Toshiki. 2002. The need for redefining Japan's government debt management policy. NRI paper no. 42. Tokyo: Nomura Research Institute.

\section{Comment Stephanie Schmitt-Grohé}

When I was invited to discuss Christopher Sims's contribution to the Inflation Targeting Conference, one of the reasons I looked very much forward to preparing the discussion - besides the fact that a Sims paper is typically a very rewarding read - was that I hoped to finally learn what exactly inflation targeting is and what exactly an inflation-targeting central bank is supposed to do. However, I soon realized that this would not happen. I have come to the conclusion that inflation targeting is a nebulous monetary policy prescription. This concept is not as clearly defined as I had hoped for, and it certainly cannot easily be tied to very precise instructions for the central bank on how to behave. Chris Sims, though, I should note, is more willing to come forward with a definition of inflation targeting than others who write on the topic. His definition of inflation targeting is "simply any commitment by the central bank to control the time path of the inflation rate or the price level, at least in the long run." In my opinion, this definition could be one of any monetary policy rather than that of inflation targeting in particular. This is because undoubtedly, any central bank strives to control the time path of inflation or the price level. With this in mind, one can then interpret the limits of inflation targeting that are presented in the Sims paper as limits that any monetary policymaker, and not just an inflation targeter, will face. Thus, the concerns raised in the Sims paper will apply very generally, making them only the more relevant.

The Sims paper analyzes two economies in which there are limits to inflation targeting. In one case inflation targeting may open the door to unintended deflation, and in the other case inflation targeting may open the door to a speculative inflation. The logical next question the paper asks is how those speculative in- and deflations can be avoided. Contrary to the existing related literature, the Sims analysis treats the central bank and the fiscal authority as independent entities, each with its own budget con-

Stephanie Schmitt-Grohé is professor of economics at Duke University and a research associate of the National Bureau of Economic Research.

I would like to thank Martín Uribe for comments. 
straint. The main contribution of the paper is to show that a central bank that lacks fiscal backing from the treasury may be more limited in its ability to achieve its goals regarding inflation than a central bank that enjoys the full financial support of the fiscal authority.

The Sims paper effectively communicates through insightful discussions that central bank independence may interfere with a central bank's ability to fight off self-fulfilling in- and deflations. The most formal presentation of this idea is given for an economy that tries to control inflation through an inertial interest rate feedback rule (see section 7.3). First, in this section it is shown that, contrary to the intentions of the central bank, the interest rate feedback rule may allow for speculative inflations. Then the paper shows that the usual remedy against speculative inflations, namely fractional reserve backing, may not work if the central bank does not have access to revenues created by the taxing power of the fiscal authority.

In what follows, I present a short review of the existing literature on limits to price-level or inflation control and on how to rule out speculative inand deflations. I then ask whether those strategies will also work under the assumption of central bank independence. I show that for the economy studied in greatest detail in the Sims paper, the one of section 7.3, it is possible to rule out speculative inflations despite the fact that the central bank is independent. What is needed, should the economy embark on a speculative inflation, is a commitment by the central bank to switch to a monetary policy that first builds central bank net worth and then pegs the price level.

\section{Can the Central Bank Alone Control the Path of Inflation?}

Given fiscal policy, one can in general distinguish three cases. In the first case, the inflation path targeted by the central bank is necessarily unsustainable under all conceivable ways of conducting monetary policy; that is, it creates too little seigniorage revenue to make fiscal policy sustainable. In the second case, the inflation path targeted by the central bank can in principle be supported as an equilibrium outcome. But some monetary policies will imply that the inflation path is not attained and instead the economy must converge either to a self-fulfilling inflation or to a self-fulfilling deflation with probability one. For example, Loyo (1999) argues that the combination of an active interest rate feedback rule and a non-Ricardian fiscal policy led Brazil to hyperinflation in the mid-1980s. In the third scenario, it could also be the case that some monetary policies will imply that the targeted inflation path is only one of several price paths that are consistent with the monetary fiscal regime. Here again there are two cases. Besides the target rate of inflation, equilibria exist with self-fulfilling inflations and deflations. For examples see the work of Brock (1974, 1975), Obstfeld and Rogoff (1983), Woodford (1994, 2003), and Benhabib, Schmitt-Grohé, and 
Uribe (2001b). The second possibility is that besides the target path of inflation there exist other bounded equilibria. Those can be of two types. One type is perfect-foresight equilibria converging to the steady state. Typically, not just a single one of those exists, but a continuum. To name but a few, examples are contained in the work of Woodford (1994); Leeper (1991); Clarida, Galí, and Gertler (2000); and Benhabib, Schmitt-Grohé, and Uribe (2001a). Another class of bounded equilibria that may exist is equilibria converging to a cycle, as shown in Benhabib, Schmitt-Grohé, and Uribe (2001a, b, 2003), or chaotic equilibria (Benhabib, Schmitt-Grohé, and Uribe, 2002b). Finally, it could be the case that the monetary policy will imply that the targeted path of inflation is the only equilibrium outcome. This scenario is the one that is desired, but as the above discussion demonstrates, this will not always be the case.

\section{What Monetary Strategies Have Been Proposed to Rule Out Speculative Inflations or Deflations?}

In the existing literature two strategies have been proposed to rule out self-fulfilling inflations. One strategy is to impose restrictions on preferences that imply that money is essential in the sense that utility would converge to negative infinity when real balances approach zero. This route has been studied (and criticized as economically unreasonable) in Brock (1974, 1975), Gray (1984), and Obstfeld and Rogoff (1983). The model analyzed in the Sims paper does not make this assumption. Rather, it makes the more plausible assumption that once liquidity becomes too expensive agents are willing to regress to barter and not use money at all. The second strategy, which is typically regarded as more compelling, for it does not rely on questionable assumptions about the nature of preferences, is to switch to a price-level peg (see Wallace [1981] and Obstfeld and Rogoff [1983]). It is the effectiveness of this second strategy that the Sims paper studies in detail in the case that the central bank lacks financial backing from the fiscal authority.

Similarly, the existing literature contains routes on how to rule out selffulfilling deflations relying on preference specifications and on monetary policy switches. One possible route is the adoption of a price-level peg. For this strategy to work, the central bank must be willing to purchase, for example, foreign exchange at a fixed price with money. Svensson (2001) has labeled this strategy of avoiding unintended deflations the "foolproof way" and has recommended it as a promising strategy for Japan to escape its deflationary trap. An alternative route to escaping the liquidity trap has been proposed by Benhabib, Schmitt-Grohé, and Uribe (2002a). They show that the switch to a positive money growth rate peg, if accompanied by the right fiscal policy, will prevent an economy from falling into a deflationary spiral. 


\section{Would Those Antispeculative Strategies Also Work When the Central Bank Is Independent of the Fiscal Authority?}

The Svensson (2001) foolproof way of avoiding a self-fulfilling liquidity trap requires that the central bank stand ready to buy (in principle, unlimited quantities of) assets in exchange for currency. From a balance sheet point of view, this strategy should provide few problems. It requires the central bank to buy financial assets with money. Since the central bank has access to unlimited amounts of money, this strategy is clearly feasible even in the absence of resource transfers from the fiscal authority. In the Sims paper, it is argued that this strategy may not be adopted because the central bank does not want to make its balance sheet longer. The reason given why a central bank may object to making its balance sheet longer is that it would make it more prone to variations in net worth stemming from variations in the real value of central bank assets. The Sims paper cites in particular the exchange rate risk associated with purchases of foreign currency-denominated bonds.

However, if the foolproof way of avoiding speculative deflations is effective, it means that prices will never start falling to begin with and the central bank will never have to actually implement the price-level peg. In this case the balance sheet considerations should play no role. Second, suppose an economy is already in a liquidity trap and contemplates the implementation of a price-level peg to prevent further declines in prices. In the self-fulfilling deflation, prices and nominal balances are declining at about the same rate (ignoring growth for the moment). But if a price-level peg is implemented, then real balances should fall (because inflation will increase from a negative quantity to zero), and with the price level pegged this means that nominal money balances must fall, leading to outflows of central bank reserves rather than inflows. That is, the balance sheet of the central bank will become shorter and not longer. (This is the famous balance-of-payments crisis argument.) The central bank may even set the price-level peg at exactly that level that will imply that nominal money balances are unchanged. To be able to achieve this, it will have to announce that the price level is pegged at a higher level than the price level in place immediately before the switch to the price-level peg. In this case, central bank independence will again not stand in the way of the quest for price stability.

Benhabib, Schmitt-Grohé, and Uribe (2002a) show that the central bank can rule out self-fulfilling deflations by switching policy to a (positive) money growth rate peg. As will become clear from the discussion in the next section, this strategy can be successful even if the net worth of the central bank is initially negative and the central bank is independent.

The central argument in the Sims paper is that a price-level peg may not rule out self-fulfilling inflations under central bank independence. Specifically, it is argued that a self-fulfilling inflation may not be averted if the central bank has negative net worth. However, this result hinges critically 
on the particular specification of monetary policy in the Sims analysis, where it is assumed that the central bank follows an inertial interest rate feedback rule. In the example studied in section 7.3 of the Sims paper, when the economy demonetizes - that is, when real balances converge to zeronominal balances are actually declining. So it is a case of a self-fulfilling inflation with shrinking nominal balances. In most existing historical examples of economies in which accelerating inflation led to demonetization of the economy, the opposite was observed. The accelerating inflation occurs in an environment in which nominal money balances are increasing, albeit at a slower rate than prices.

This feature of the Sims analysis is important. For only if $\dot{M}<0$ is net worth of the central bank shrinking along the hyperinflationary path. To see this, let $w(t)$ denote the ratio of central bank assets to central bank liabilities - that is, in the notation of the Sims paper $w(t)=P(t) F_{G}(t) / M(t)$. It follows that $\dot{w} / w=\pi+\dot{F}_{G} / F_{G}-\dot{M} / M$. Using the central bank's budget constraint, equation (22) in the Sims paper, and assuming that the central bank makes no transfers to the fiscal authority, $\tau_{B}=0$, it follows that $\dot{w} / w=(\pi+$ $\rho)+\dot{M} / M(1 / w-1)$. Suppose that initially the central bank's net worth is negative, so that $0<w<1$. Then, in a self-fulfilling inflation, the balance sheet of the central bank is deteriorating only if nominal money balances are falling. ${ }^{1}$ This seems to suggest that in cases in which in a self-fulfilling hyperinflation nominal money balances are increasing central bank independence may not be an obstacle to ruling out self-fulfilling hyperinflations.

In the section that follows, I present an example of a self-fulfilling hyperinflation in which along the hyperinflationary path nominal money balances are increasing and argue that in this case one can rule out those inflationary paths through fractional reserve backing even in the case that the central bank is independent. The reason is that if nominal money balances are increasing on the way to a speculative inflation, the central bank accumulates real resources. At some point it must then be the case that the net worth of the central bank becomes nonnegative. That is, we must have that at some point $P F^{G} / M \geq 1$. At that exact instance, the central bank could switch to a pure price-level peg. This price-level peg will be sustainable because the central bank could, if need be, redeem the entire stock of money for reserves.

\section{An Example of Ruling Out Speculative Inflations under Central Bank Independence}

\section{The Household}

The household's problem is almost the same as the one described in section 7.3 of the Sims paper. The main difference is that it is assumed that

1. Note that $\pi+\rho$ denotes the nominal interest rate, which in equilibrium must be nonnegative. 
time is discrete, whereas in the Sims paper time is continuous. Without loss of generality, one can assume that households can only hold two types of asset - money and foreign bonds - rather than three, as is assumed in the Sims paper. Under this assumption the household's budget constraint can be written as ${ }^{2}$

$$
\max \sum_{t=0}^{\infty} \beta^{t} \ln c_{t}
$$

subject to

$$
\begin{gathered}
\frac{M_{t-1}}{P_{t}}+\left(1+\rho_{t-1}\right) F_{t-1}^{P}+y_{t}+\tau_{t}=c_{t}\left[1+\psi\left(v_{t}\right)\right]+\frac{M_{t}}{P_{t}}+F_{t}^{P} \\
v_{t}=\frac{P_{t} c_{t}}{M_{t}} \\
\lim _{j \rightarrow \infty}\left(\prod_{s=t}^{j-1} \frac{1}{1+\rho_{t+s}}\right)\left[\frac{M_{t+j-1}}{P_{t+j}}+\left(1+\rho_{t+j-1}\right) F_{t+j-1}^{P}\right] \geq 0 .
\end{gathered}
$$

The household takes $P_{t}, \rho_{t}, y_{t}$, and $\tau_{t}$ as exogenously given. The initial conditions of the household are $M_{-1}$ and $\left(1+\rho_{-1}\right) F_{-1}^{P}$.

The Lagrangian of the household's maximization problem can then be written as

$$
\begin{aligned}
& \mathscr{L}=\sum_{t=0}^{\infty} \beta^{t}\left\{\ln c_{t}+\lambda_{t}\left[-c_{t}\left(1+\psi\left[\frac{{ }_{t} c_{t}}{M_{t}}\right]\right)-\frac{M_{t}}{P_{t}}\right.\right. \\
&\left.\left.-F_{t}^{P}+\frac{M_{t-1}}{P_{t}}+\left(1+\rho_{t-1}\right) F_{t-1}^{P}+y_{t}+\tau_{t}\right]\right\} .
\end{aligned}
$$

The first-order conditions are equations (1), (2), and (3) holding with equality and

$$
\begin{gathered}
\frac{1}{c_{t}}=\lambda_{t}\left[1+\psi\left(v_{t}\right)+v_{t} \psi^{\prime}\left(v_{t}\right)\right] \\
1-v_{t}^{2} \psi^{\prime}\left(v_{t}\right)=\beta \frac{\lambda_{t+1}}{\lambda_{t}} \frac{P_{t}}{P_{t+1}} \\
\lambda_{t}=\left(1+\rho_{t}\right) \beta \lambda_{t+1}
\end{gathered}
$$

The Fiscal Authority

We assume that the fiscal authority does not issue bonds and simply rebates any seigniorage income it receives from the central bank to private households - that is,

2. The notation follows that of the Sims paper. 


$$
\tau_{t}=\tau_{t}^{B} \text {. }
$$

This assumption about the nature of fiscal policy is consistent with the treatment of fiscal policy in the Sims paper. The Sims paper, however, is less specific and simply states that "a passive fiscal policy keeps real debt under control regardless of the path of inflation." 3

\section{The Monetary Authority}

At the end of period $t$, the central bank has real assets in the amount of $F_{t}^{G}$. Following the Sims paper, I assume that its period-by-period budget constraint is given by

$$
F_{t}^{G}=\left(1+\rho_{t-1}\right) F_{t-1}^{G}+\frac{M_{t}-M_{t-1}}{P_{t}}-\tau_{t}^{B} .
$$

Central bank independence is interpreted in the Sims paper to mean that $\tau_{t}^{B}$ must be nonnegative; that is, the central bank cannot get backing for its liabilities in the form of transfers from the fiscal authority. ${ }^{4}$ For simplicity, I will assume further that

$$
\tau_{t}^{B}=0
$$

\section{Equilibrium}

A perfect-foresight equilibrium is a set of sequences $\left\{c_{t}, v_{t}, M_{t}, P_{t}, F_{t}^{G}\right.$, $\left.F_{t}^{P}, \lambda_{t}, \tau_{t}, \tau_{t}^{B}\right\}$ given exogenous $\left\{y_{t}, \rho_{t}\right\}$ and the initial values of $M_{-1},(1+$ $\left.\rho_{-1}\right) F_{-1}^{G}$, and $\left(1+\rho_{-1}\right) F_{-1}^{P}$ satisfying equations (1)-(9), with equation (3) holding with equality, and one additional equation describing monetary policy.

To characterize the equilibrium dynamics, use equation (4) to eliminate $\lambda_{t}$ from equation (5) to obtain

$$
1-v_{t}^{2} \psi^{\prime}\left(v_{t}\right)=\beta \frac{1+\psi\left(v_{t}\right)+v_{t} \psi^{\prime}\left(v_{t}\right)}{1+\psi\left(v_{t+1}\right)+v_{t+1} \psi^{\prime}\left(v_{t+1}\right)} \frac{c_{t} P_{t}}{c_{t+1} P_{t+1}} .
$$

Using equation (2) this expression can be rewritten as

$$
1-v_{t}^{2} \psi^{\prime}\left(v_{t}\right)=\beta \frac{1+\psi\left(v_{t}\right)+v_{t} \psi^{\prime}\left(v_{t}\right)}{1+\psi\left(v_{t+1}\right)+v_{t+1} \psi^{\prime}\left(v_{t+1}\right)} \frac{v_{t}}{v_{t+1}} \frac{M_{t}}{M_{t+1}} .
$$

3. Central bank independence and non-Ricardian fiscal policy can give rise to default by the fiscal authority. See Uribe (2002) for a characterization of the equilibrium behavior of default under central bank independence and alternative non-Ricardian policy regimes.

4. A slightly different interpretation of central bank independence is that the central bank chooses $\tau_{t}^{B}$ subject to the constraint that it has to be nonnegative. For if the fiscal authority could determine the magnitude of $\tau_{t}^{B}$, then the fiscal authority would effectively gain control over net worth of the central bank and could, for example, finance fiscal deficits with reserves. For the arguments that follow, it is important that the central bank, and not the fiscal authority, control the size of $\tau_{t}^{B}$. 
Consider now the case that the central bank follows a money growth rate peg by setting $M(0)$ and then letting $M_{t}$ evolve according to the rule

$$
M_{t+1}=\mu M_{t} ; \quad \mu>1,
$$

where $\mu$ denotes the gross growth rate of the money supply. For this monetary policy specification, equation (10) is a first-order difference equation in one endogenous variable, $v_{t}$. The steady state of that equation solves

$$
1-v^{* 2} \psi^{\prime}\left(v^{*}\right)=\beta \mu^{-1},
$$

where $v^{*}$ denotes the steady-state value of consumption velocity. For the particular functional form of $\psi(v)$ assumed in the Sims paper - that is, $\psi(v)$ $=\gamma v /(1+\phi v)$-we have

$$
v^{*}=\frac{\sqrt{1-\beta \mu^{-1}}}{\sqrt{\gamma}-\phi \sqrt{1-\beta \mu^{-1}}} .
$$

The existence of a steady state in which velocity is positive requires that $\gamma / \phi^{2}>1-\beta \mu^{-1}$. One can show that if a steady state exists, it is unique. Next I wish to show that for any $v(0)>v^{*}$, equation (10) implies that as long as the money growth rate peg is in place $v_{t+1}>v_{t}$. To see this, rewrite equation (10) as

$$
\left[1+\psi\left(v_{t+1}\right)+v_{t+1} \psi^{\prime}\left(v_{t+1}\right)\right] v_{t+1}=\frac{\beta}{\mu\left[1-v_{t}^{2} \psi^{\prime}\left(v_{t}\right)\right]}\left[1+\psi\left(v_{t}\right)+v_{t} \psi^{\prime}\left(v_{t}\right)\right] v_{t} .
$$

Let $G\left(v_{t}\right)=\left[1+\psi\left(v_{t}\right)+v_{t} \psi^{\prime}\left(v_{t}\right)\right] v_{t}$ and $F\left(v_{t}\right)=\beta /\left\{\mu\left[1-v_{t}^{2} \psi^{\prime}\left(v_{t}\right)\right]\right\}\left[1+\psi\left(v_{t}\right)+\right.$ $\left.v_{t} \psi^{\prime}\left(v_{t}\right)\right] v_{t}$. Note that both $G(\cdot)$ and $F(\cdot)$ are increasing in $v$. Clearly, at $v=$ $v^{*}, G(v)=F(v)$. However, for $v>v^{*}, F(v)>G(v)$ because $\beta /\left(\mu\left[1-v_{t}^{2} \psi^{\prime}\left\{v_{t}\right\}\right]\right.$ $>1$. Thus, in order for $v_{t}$ to satisfy equilibrium condition (10) in the case that $v_{0}>v^{*}$, it must be the case that $v_{t}$ is increasing over time. If this explosive path for $v$ can be supported as an equilibrium outcome, then speculative inflations are possible in this economy. For simplicity, we assume that $\beta\left(1+\rho_{t}\right)=1$ for all $t$. It follows from equation (4) that $\lambda_{t}=\lambda_{0}$ for all $t \geq 0$. By equation (4) the time path for consumption is then given by $c_{t}=1 / \lambda_{0} /$ $\left(1+\psi\left[v_{t}\right]+v_{t} \psi^{\prime}\left[v_{t}\right]\right)$ for all $t$. From this relation and the definition of velocity it follows that $P_{0}=v_{0} M_{0} \lambda_{0}\left(1+\psi\left[v_{0}\right]+v_{0} \psi^{\prime}\left[v_{0}\right]\right)$. Iterating equation (1) forward and using equation (1) one obtains a present discounted value constraint of the form $\Sigma_{\mathrm{t}=0}^{\infty} q_{t}\left(y_{t}+\tau_{t}-\left[1+\psi\left(v_{t}\right)\right] c_{t}-M_{t} / P_{t}\left[R_{t+1}-1\right] / R_{t+1}\right)+$ $M_{-1} / P_{0}+(1+\rho) F_{-1}^{P}=0$, where $q_{t} \equiv \prod_{s=0}^{t-1}\left(1 \rho_{s}\right)^{-1}$ and $R_{t+1} \equiv\left(1+\rho_{t}\right) P_{t+1} / P_{t}=$ $1 /\left(1-v_{t}^{2} \psi^{\prime}\left[v_{t}\right]\right)$. Using the definition of velocity to eliminate $M_{t} / P_{t}$ and equation (4), we can rearrange this expression to get $\sum_{\mathrm{t}=0}^{\infty} q_{t}\left(y_{t}+\tau_{t}-[1+\right.$ $\left.\left.\psi\left\{v_{t}\right\}\right] /\left[1+\psi\left\{v_{t}\right\}+v_{t} \psi^{\prime}\left\{v_{t}\right\}\right] / \lambda_{0}-1 /\left[1+\psi\left\{v_{t}\right\}+v_{t} \psi^{\prime}\left\{v_{t}\right\}\right] / \lambda_{0} / v_{t}\left[R_{t+1}-1\right] / R_{t+1}\right)$ $+M_{-1} / v_{0} / M_{0} /\left(1+\psi\left[v_{0}\right]+v_{0} \psi^{\prime}\left[v_{0}\right] / y_{0}+(1+\rho) F_{-1}^{P} .=0\right.$. Given a time path for $v_{t}$, this expression uniquely determines $\lambda_{0}$. Finally, note that because nominal money balances are not shrinking $(\mu \geq 1)$ over time, central bank net wealth is increasing; that is, $P_{t+1} F_{t+1}^{G} / M_{t+1}>P_{t} F_{t}^{G} / M_{t}$. 
The arguments just presented establish that a self-fulfilling inflation can be supported as an equilibrium outcome. The consequence of this result is that the central bank would not have control over inflation. This is because any $v_{0} \geq v^{*}$ constitutes a perfect-foresight equilibrium. The existence of self-fulfilling inflations in economies in which monetary policy takes the form of a money growth rate peg is a well-known result; see, for example, Brock (1974, 1975), Obstfeld and Rogoff (1983), and Woodford (1994). Equally well known are ways to rule such speculative inflations out. In particular, Wallace (1981) and Obstfeld and Rogoff have suggested using fractional backing as a way to rule out speculative inflations. Under a policy of fractional backing the central bank commits to adopt a price-level target at some price level $\bar{P}$ should the price level pass a certain threshold. For this threat to be credible it must be the case that, at the moment the price-level target is implemented, the central bank has sufficient reserves on hand to exchange the entire money stock in circulation at the preannounced price; that is, we need that $\bar{P} F_{t-1}^{G} \geq M_{t-1}$, where $t$ is the first period in which the price-level peg is in place. In standard analysis the fiscal and monetary authority are treated as a unit with a single consolidated budget constraint. In this case, the solvency requirement of the central bank is of no concern, for the central bank is implicitly guaranteed support from the fiscal authority (in the form of tax revenue) to redeem money for real assets should there be a need.

Our concern here is how we can rule a self-fulfilling inflation in this model even if the central bank is independent. Suppose that the central bank announces that it will follow a money growth rate peg with $\mu>1$ and that should $v_{0}>v^{*}$, then the money growth rate peg would only stay in place until $P_{t} F_{t}^{G} \geq M_{t}$. Let $T$ denote the first period in which $P_{t} F_{t}^{G} \geq M_{t}$; then the central bank will keep the money growth rate peg until period $T$, and from period $T+1$ on, it will follow a price-level peg of the form $P_{t}=$ $P_{T}$ for all $t>T$. Then we know from equation (5) that $1-v_{T}^{2} \psi^{\prime}\left(v_{T}\right)=\beta$, which implies that $v_{T}<v^{*}$. At the same time, with $v_{0}>v^{*}$ equilibrium condition (31) can only be satisfied if $v_{T}>v_{T-1}>v_{T-2}>\ldots>v_{0}>v^{*}$. But both of those conditions can never be satisfied at the same time. Therefore, $v_{0}>$ $v^{*}$ cannot be supported as a perfect-foresight equilibrium. It follows that fractional backing is capable of ruling out a self-fulfilling inflation even in the case in which the central bank starts out with negative net worth and never receives an injection of resources from the fiscal authority.

Finally, suppose that a central bank wishes to follow an interest rate feedback rule like the one studied in the Sims paper. One possible strategy to rule out self-fulfilling inflations in this case is to commit to switching to a money growth rate peg should central bank net worth fall too low, and in addition threaten to switch monetary policy yet again to a price-level target once the net worth of the central bank is sufficiently large.

The reason why fractional reserve backing does not work in the econ- 
omy presented in section 7.3 of the Sims paper is that under the interest rate policy, net worth of the central bank may be falling along the self-fulfilling hyperinflation (see figure 7.2 of the Sims paper). Specifically, the analysis of the Sims paper shows that if a central bank starts with sufficiently negative net worth, it will never be able to reach solvency when the economy falls into a speculative inflation, and hence the central bank will never be able to announce a credible price-level peg. However, under a positive money growth rate peg, even under a self-fulfilling inflation, nominal money balances increase over time, and therefore the net worth of the central bank, $P_{t} F_{t}^{G} / M_{t}$, improves with time.

\section{References}

Benhabib, Jess, Stephanie Schmitt-Grohé, and Martín Uribe. 2001a. Monetary policy and multiple equilibria. American Economic Review 91 (March): 167-86.

. 2001b. The perils of Taylor rules. Journal of Economic Theory 96 (February): $40-69$.

. 2002b. Chaotic interest rate rules. American Economic Review Papers and Proceedings 92 (May): 72-78. $535-63$.

. 2003. Backward-looking interest-rate rules, interest rate smoothing, and macroeconomic instability. Journal of Money, Credit and Banking 35 (December): $1379-1412$.

Brock, William. 1974. Money and growth: The case of long-run perfect foresight. International Economic Review 15 (October): 750-77.

- 1975. A simple perfect foresight monetary model. Journal of Monetary Economics 1 (April): 133-50.

Clarida, Richard, Jordi Galí, and Mark Gertler. 2000. Monetary policy rules and macroeconomic stability: Evidence and some theory. Quarterly Journal of Economics 115 (February): 147-80.

Gray, Jo Anna. 1984. Dynamic instability in rational expectations models: An attempt to clarify. International Economic Review 25 (February): 93-122.

Leeper, Eric. 1991. Equilibria and active and passive monetary and fiscal policies. Journal of Monetary Economics 27 (February): 129-47.

Loyo, Eduardo. 1999. Tight money paradox on the loose: A fiscalist hyperinflation. Harvard University, John F. Kennedy School of Government. Manuscript, June.

Obstfeld, Maurice, and Kenneth Rogoff. 1983. Speculative hyperinflations in maximizing models: Can we rule them out? Journal of Political Economy 91: 675-87.

Svensson, Lars. 2001. The zero bound in an open economy: A foolproof way of escaping from a liquidity trap. Monetary and Economic Studies 19:277-312.

Uribe, Martín. 2002. A fiscal theory of sovereign risk. NBER Working Paper no. 9221. Cambridge, Mass.: National Bureau of Economic Research, September.

Wallace, Neil. 1981. A hybrid fiat-commodity monetary system. Journal of Economic Theory 25 (December): 421-30.

Woodford, Michael. 1994. Monetary policy and price-level determinacy in a cashin-advance economy. Economic Theory 4:345-80.

- 2003. Price-level determination under interest-rate rules. In Interest and prices: Foundations of a theory of monetary policy, 61-138. Princeton, N.J.: Princeton University Press. 


\section{Discussion Summary}

Frederic Mishkin suggested that risks to financial stability imposed as important limits on monetary policy as did fiscal stability. In recent work with Guillermo Calvo, the authors argued that in emerging economies problems related to financial and fiscal policies were of a larger order of magnitude compared to problems related to monetary policy. Another example was the recent experience of Brazil, where depreciation in response to political uncertainty forced the inflation target to be raised. He agreed with Sims on the important role that the central bank's balance sheet had to play, and pointed out that the Bank of Japan had explained in this regard its reluctance to pursue more expansionary monetary policies.

Masaaki Shirakawa pointed out that in the current situation in Japan, with nominal interest rates even at long maturities near zero, the distinction between bonds and money becomes blurred, meaning that distinction between monetary policy and fiscal policy is also becoming blurred. At the moment, the amount of Japan government bonds held by the Bank of Japan was about 60 percent of the monetary base, which according to conventional measures could raise questions about the soundness of the Bank of Japan's balance sheet. The Bank of Japan had already engaged in substantial quantitative easing, expanding the size of its balance sheet from 15 percent of GDP four years ago to about 26 percent now. A related question was whether the Bank of Japan should take on different forms of risk by purchasing assets other than JGBs. For the Bank of Japan to engage in some form of fiscal policy, it would probably need some kind of commitment from the government to guarantee its solvency, if the general public questioned the ability of a central bank whose capital position is impaired to pursue adequate monetary policy.

Bennett McCallum questioned the view that transparency was the main advantage of inflation targeting, and argued that from the mid-1970s until the start of EMU the Bundesbank had been both the most successful central bank in terms of inflation control and one of the least transparent.

Christopher Sims responded that central banks usually faced legal restrictions on trading money for real assets, which pointed to the need for monetary-fiscal coordination in preventing deflationary spirals. This pointed to further need to rethink the boundaries between fiscal and monetary policy, and the proper role of central bank independence. 
